\title{
Evaluation (POE) of Yildiz Technical University (YTU) School of Foreign Languages (SFL)
}

\author{
Muzaffer Tolga Akbulut, Cigdem Polatoglu and Ayfer Aytug \\ Faculty of Architecture, Yildiz Technical University, Besiktas 34 349, Istanbul, Turkey
}

\begin{abstract}
This paper deals with the post-occupancy performance evaluation of the SFL (School of Foreign Languages) that was designed by the authors and is located within the YTU (Yildiz Technical University) Davutpaşa campus in Istanbul. After the completion and occupation of the building, project review came into question and a POE was performed. Post-occupancy performance evaluation tries to answer the questions of space provision for social interaction: "How is this building working?" "Is it intended?" "How can it be improved?" and "How can future buildings be improved?" Answers to these vital questions are searched under four main sections. In the first section, the study discusses the physical location and functional properties of the building, in the second, the design decisions of the building are discussed in the context of and design principles, in the third, the method of performance evaluation is explained, and in the final section, the results are analyzed and discussed. These results will lead to a path to improve the quality of the building.
\end{abstract}

Key words: POE (Post Occupancy Evaluation), design principles of school buildings, social interaction in education.

\section{Introduction}

Founded in 1911, YTU is one of the leading state universities of Istanbul, Turkey. The university campus was initially located in the city center which grounds on the last Ottoman Palace, the Yildiz Palace. However, in time, the expansion requirements of the central campus of the university outgrew the physical capacity of the campus. The new-additional campus area known as the Davutpaşa Barracks given to YTU is also another historical site that was used by the Ottoman Empire and is located amidst an industrial zone. The Architecture faculty of YTU has undertaken the responsibility of the site planning of Davutpaşa and the design of the new faculty buildings.

The main objectives of the Davutpaşa campus design are; to provide an outward display of the importance of technology in a technical university setting and to emphasize the university's institutional

\footnotetext{
Corresponding author: Muzaffer Tolga Akbulut, Dr., assistant professor, research fields: architectural design, earthquake resistant architecture, building theory and design, housing, post occupancy evaluation. E-mail: mtolga@yildiz.edu.tr.
}

identity. An objective for the university is to enable YTU students to follow publications in English throughout their careers and to be able to express themselves fluently in verbal and written English. Therefore, students who are not able to pass the English sufficiency exams are offered English courses during their first year (preparation year) in the university to enable them to bring their language skills up to the desired level. Hence, the completion of the SFL (School of Foreign Languages) at the Davutpaşa campus has been given priority in the design and construction stages.

The SFL has the distinction of being the first building encountered by students each year as they register at the university. In addition to being the venue for the formal foreign language education, the SFL has institutional significance through its role in establishing an institutional identity, its function for organizing the social interchange among incoming students who will in subsequent years go off to different faculties, and providing a sense of belonging for students. 
Under the SFL Project, there are 114 classrooms and 18 audio-visual classes for 15 students, instructor's offices, administrative units, a library, a multi-purpose hall, self-access, cafeteria, service units and an inner street that links the various venues and an underground parking. $2 / 3$ of the building has been completed at the first stage. When the whole building is completed, the building will have an enclosed space of approximately $18.500 \mathrm{~m}^{2}$. SFL hosted its first students at 2003-2004 academic years (Fig. 1).

\section{The Fundamental Design Principles of SFL}

Two basic axes of motion that underlie the design decisions concerning the School of Foreign Languages are:

- The building should define and reflect the identity of the university (Affect).

There is an effort to reflect the identity and technical characteristics of the university in the geometrical shape, assembly, choice of materials and construction details used in the design.

Towards this end, the design considered for the SFL building has been directly affected by structural decisions, the choice of materials and Turkey's geological characteristics.

Turkey is located on a seismic zone, this situation had always been overlooked till lately and every time a major earthquake occurred in Turkey, Istanbul was confronted with severe casualties and economic losses [1]. Therefore, earthquake and ground effects were taken into consideration in the formation of the building, and, to the extent possible, the plan geometry has been made up of basic and compact forms. A square design was chosen, in the educational blocks, as this displays the same rigidity in all directions and shows better behavior under earthquake stresses. Steel construction is chosen as construction system for the inner street, while reinforced concrete is used in all other blocks. Fibreconcrete precast materials have been used on the façade. Granite was used as the flooring material for the inner street and hallways and linoleum was used for the classrooms, admin and academic unit rooms. Different textures were sought for the walls and the fibreconcrete material and plaster used on the outer walls were used on the educational blocks-side of the inner street, thereby providing outdoor-indoor transition (color variety was kept to a minimum, natural colors were preferred, while some contrast was sought within the building — burgundy, oxidized yellow, dark green). These colors were selected regarding the results of various researches [2];

- The building should be designed in accordance with formal and informal educational principles and provision for social interaction (Spatial Organization).

Educational planning decisions were made on the basis that foreign language training is a very long, painstaking, an effort-intensive activity and that the success of foreign language education rests on language practice being embedded into daily life.

Modern campus and educational buildings comprise new site planning principles that are based on new educational philosophies and pedagogical principles. Schools of the future are defined, on the one hand, as core social centers in a study undertaken by the OECD, and on the other hand, as focused learning centers [3]. Lackney [4] also underlying premise that all learning environments should be learner-centered, developmentally-appropriate and age-appropriate, safe,

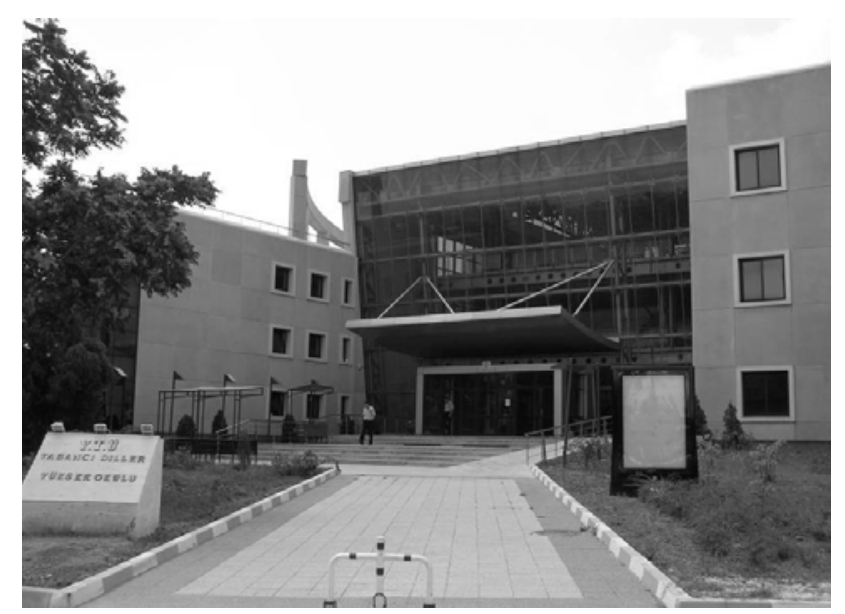

Fig. 1 The main entrance axe of School of Foreign Languages (photo: M. Tolga Akbulut). 
comfortable, accessible, flexible and equitable in addition to being cost effective in his study "Thirty-Three Educational Design Principles for Schools \& Community Learning Centers" that he completed in Educational Institute Mississippi State University sponsored by NCEF (national clearinghouse for educational facilities). Empirical studies developed on the scope of educational research show that school building conditions, such as spatial configurations, acoustics, heating, lighting and air quality have an impact on learning since they affect students and teachers performance and attitudes [5].

In scope of these studies, the traditional foreign language education at YTU is to be complemented by informal activities and the building is to be a social center of attraction for the entire campus. From this point of view the most important design principle serving this purpose is the inner street and atriums that affects the overall shape of the building. Beside these design decisions, universal design criteria are applied to the whole building design. Building access is facilitated through a wheelchair ramp and vertical movement in the building is provided through an elevator. Additionally, there are rest rooms for the disabled on each floor.

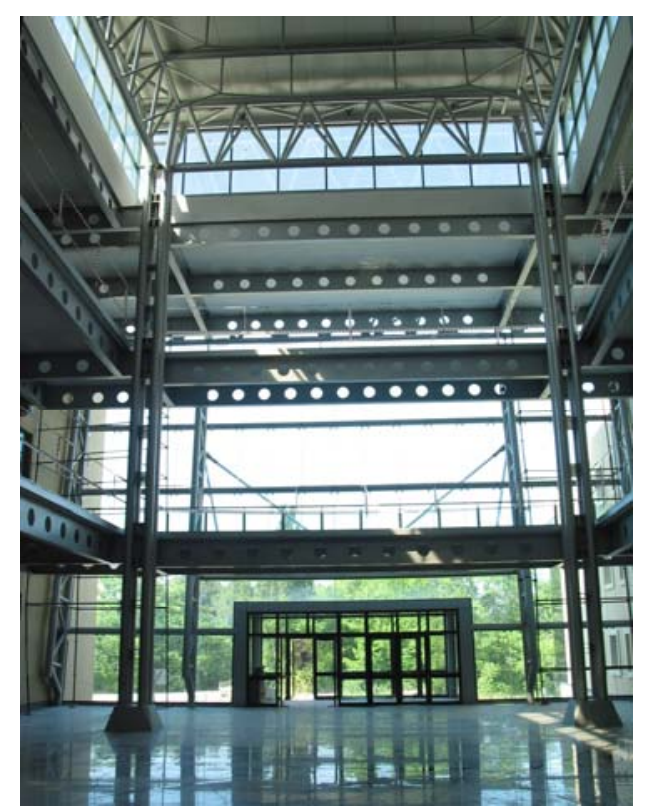

Fig. 2 The inner street (photo: M. Tolga Akbulut).

\subsection{Inner Street}

Circulation areas such as hallways and corridors are a costly percentage of a school building. As Lackney mentioned circulation areas can double as an active learning space for the school that gives increase opportunities for positive social interaction [4]. Arranging central activity nodes that connect short paths is one strategy for maintaining visual supervision without creating long institutional-style corridors. The inner street is designed in this concept; small-scale common areas are tied to the main access. The inner street, which is the fundamental feature of the design, is intended to contribute to informal education and foster friendship, solidarity, sharing and self-confidence among students (Fig. 2).

Thereby, it is intended to engender the awareness of being a part of YTU. In this context, the basic decisions regarding the inner street and the roles that it is expected to assume can be summarized as below:

General architectural formation is set up as an inner street that constitutes the entrance axis, educational blocks on the right and the left that open to this street, and the location of administrative units and educational support units on the other side.

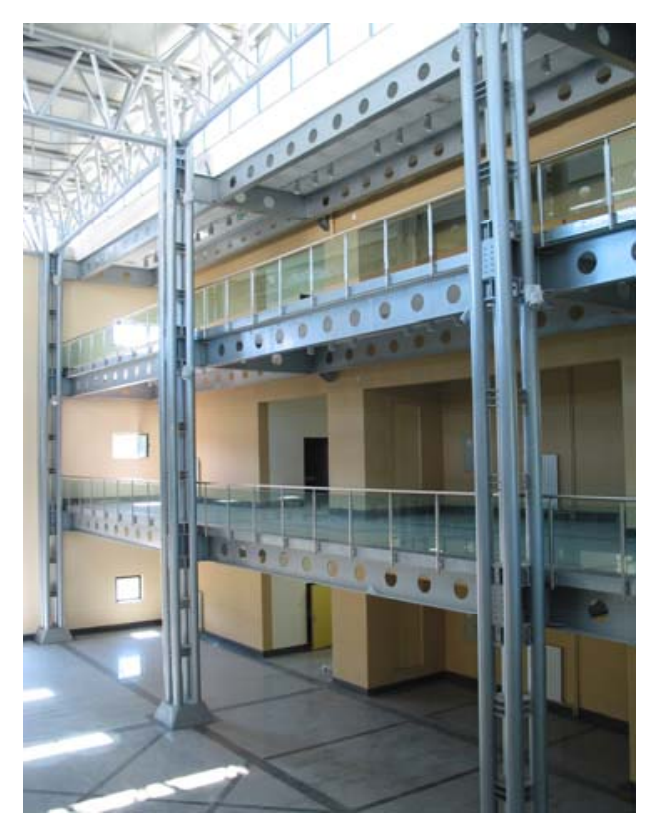


The inner street will become a focal point for activities while establishing the interfunctional vertical and horizontal transition. Another important characteristic of the inner street is that being; central and transparent, it lends itself to visual communication and supervision (Fig. 3). Small-scale common areas are tied to the main access.

In line with the multi-function roles to be assumed by the inner street and the specifics of the ground, a steel construction system is preferred in order to render the building lighter and more transparent and the main entrance façade is designed as glass in order to render this site more transparent and luminous.

The inner street is a multi-faceted social, cognitive and interactive learning area.

The inner street assumes different functions in the three levels of the building. On the ground floor, in addition to being a means of getting from one location to the other, it is a place for people to meet each other. Towards this end, it combines with the foyer of the main conference hall and establishes a strong connection with the cafeteria, which overflows into the internal street. This relationship is supported by the choice of furniture. This space is furnished with freeform and circular seats placed opposite one another in order to encourage informal interaction. The entrance hall is dedicated to activities such as art exhibitions and book sales. Additionally, the seating plan at the cafeteria also enhances this effect. At the garden level, the activities can be spread internally or externally. The amphitheater organization and social activities are outside, in the garden. In the upper floors, visual communication is established through the use of an open corridor and workspaces that are set up in the corridor.

\subsection{The Atriums and Educational Blocks}

The main design criteria of the atriums are to organize educational islands around social activity cores (Fig. 4). Each atrium has a square design and

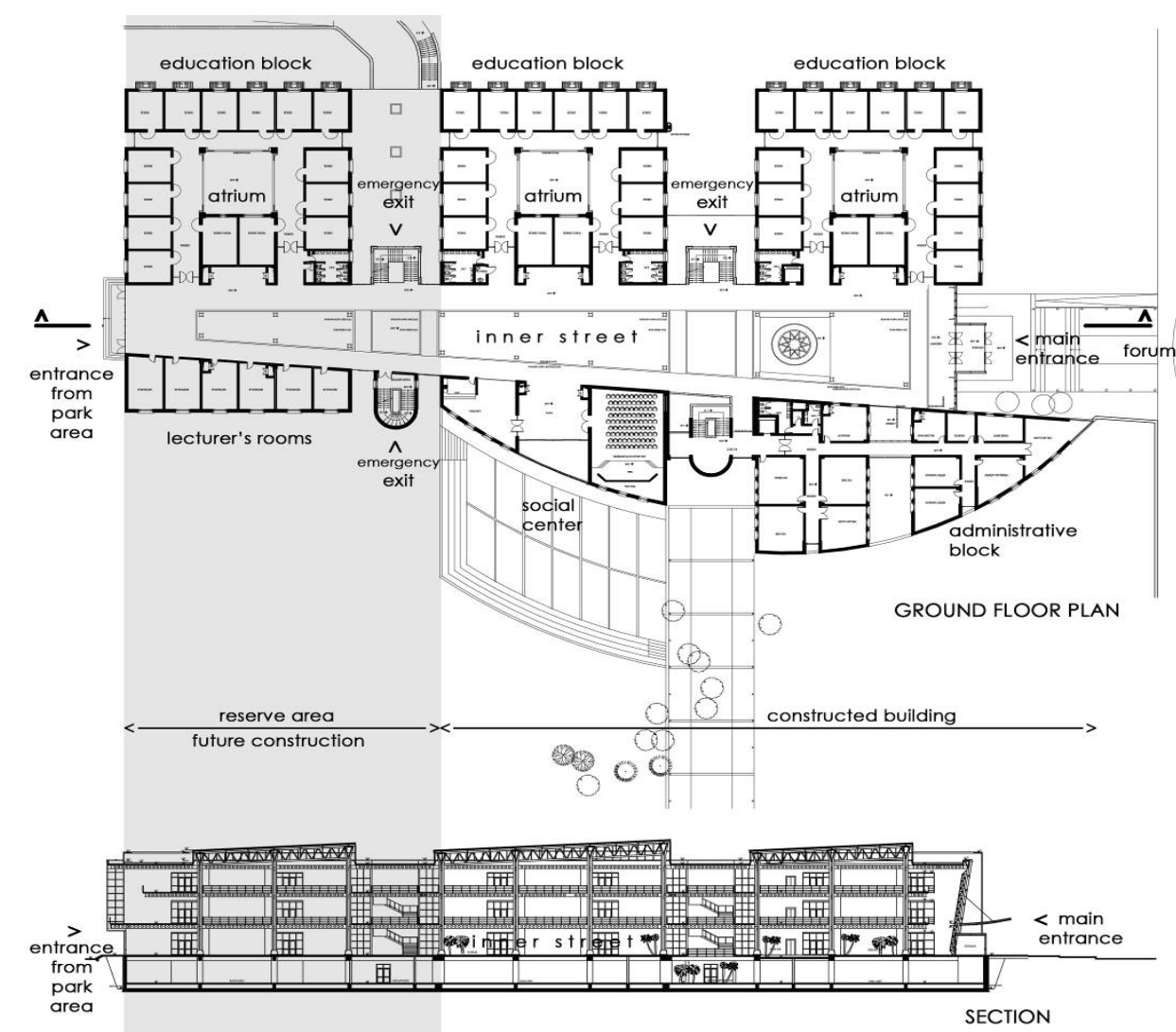

Fig. 3 Ground floor plan and longitudinal section of School of Foreign Languages (designed by the authors). 
vertically cubical. In each educational block, there are 39 classrooms and eight audio-visual halls for 15 students each. The classroom-seating plan is flexible and in accordance with this, seats with armrests were envisaged.

\section{The Procedure of the Study, POE (Post Occupancy Evaluation) in SFL}

A questionnaire with students and faculty was taken in 2009 (due to restoration changes, the POE evaluation could managed after five years of the occupation of the building) to gauge Post-Occupancy performance evaluation.

\subsection{Subjects and Application}

118 students participated in the questionnaire. As it was seen that sex was not a distinguishing feature in the pilot questionnaires, this variable was not evaluated in the final questionnaire. Sampling methodology ensured participation from each class and the random picking of respondents. The frame of the POE is formed according to leading literature in this field [6-9].

Observation on site, interview with administrative and standard questionnaire was applied with students.
The questionnaire consists of 20 questions in two overall sections that scrutinize the SFL.

- Section 1. General Building Features (14 questions);

- Section 2. Social Areas (six questions)

The questionnaire questions were organized in accordance with the below two FDP (fundamental design principles);

- FDP 1. Affect (Visual quality, identity);

- FDP 2. Spatial organization (Function, Dimension, Social interaction).

Students were asked to answer questions on a scale of five scales (strongly agree, agree, neither/nor, disagree and strongly disagree). However, respondents were asked to provide detailed feedback on the building and its specific components through open-ended questions. The results were evaluated by SPSS (Statistical Package for the Social Sciences), for calculating Arithmetic means and Factor Analysis and a meeting was held with teachers and the administration. In the meeting, it is noted that the input of these educational professionals regarding the approach to foreign language education, the effective use of existing locations, and the demand for new locations and other general requests.

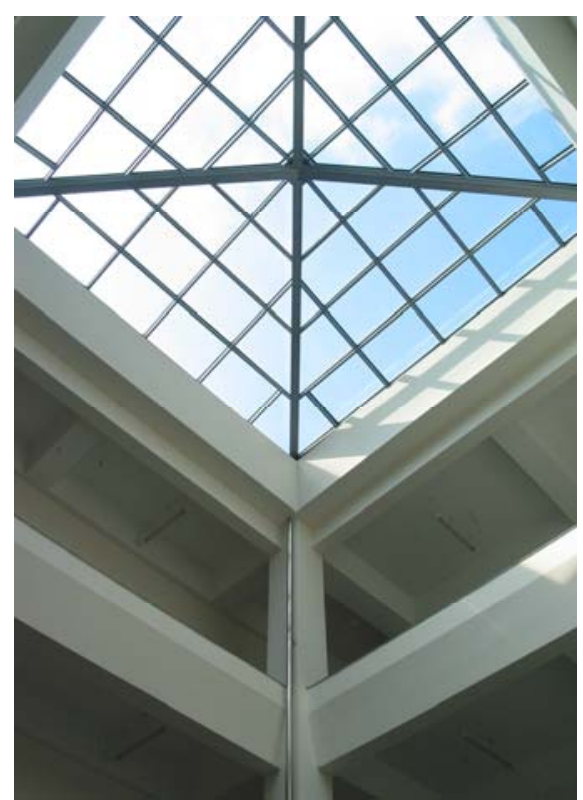

Fig. 4 Atrium, classrooms around the corridor and skylight (photo: M. Tolga Akbulut). 


\subsection{Data Analysis}

The results of the questionnaires have been determined from the examination of the arithmetic means of the preferences of the students (Graphic 1: Arithmetic Mean Distribution). The responses of all subjects have also been evaluated for Factor Analysis. Factor analysis have been executed by using "Rotated
Component Matrix: Varimax with Kaiser Normalization" and "Extraction Method: Principal Component Analysis" sub programs of the SPSS (Statistical Package for the Social Sciences) programme. The aim of the factor analysis has been to determine the factor groups in connection with the measurement of the different effect and perception of building sections (Table 1: Factor Analyses).

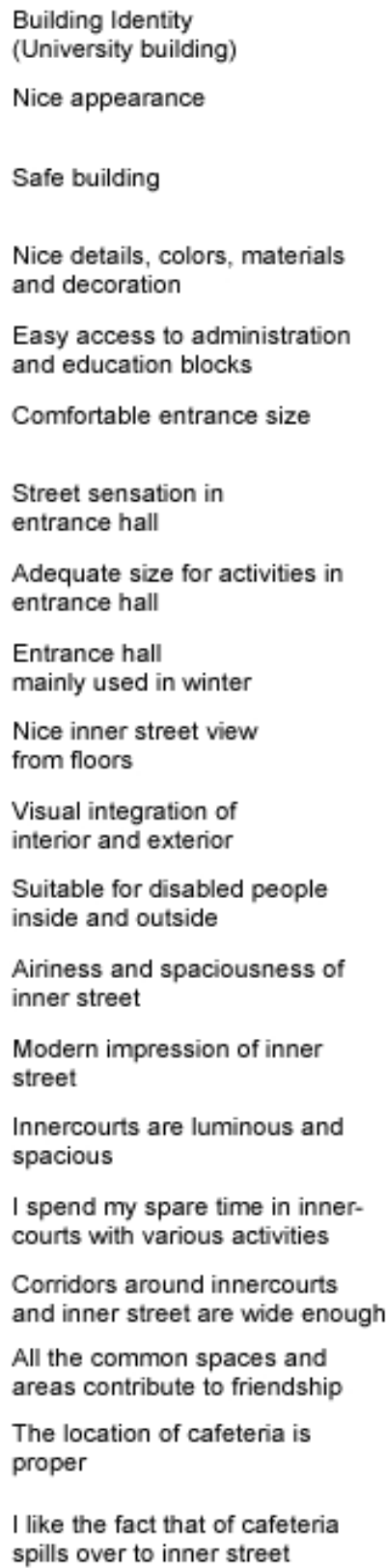

I spend my spare time in innercourts with various activities

Corridors around innercourts and inner street are wide enough

All the common spaces and areas contribute to friendship

The location of cafeteria is proper

I like the fact that of cafeteria spills over to inner street

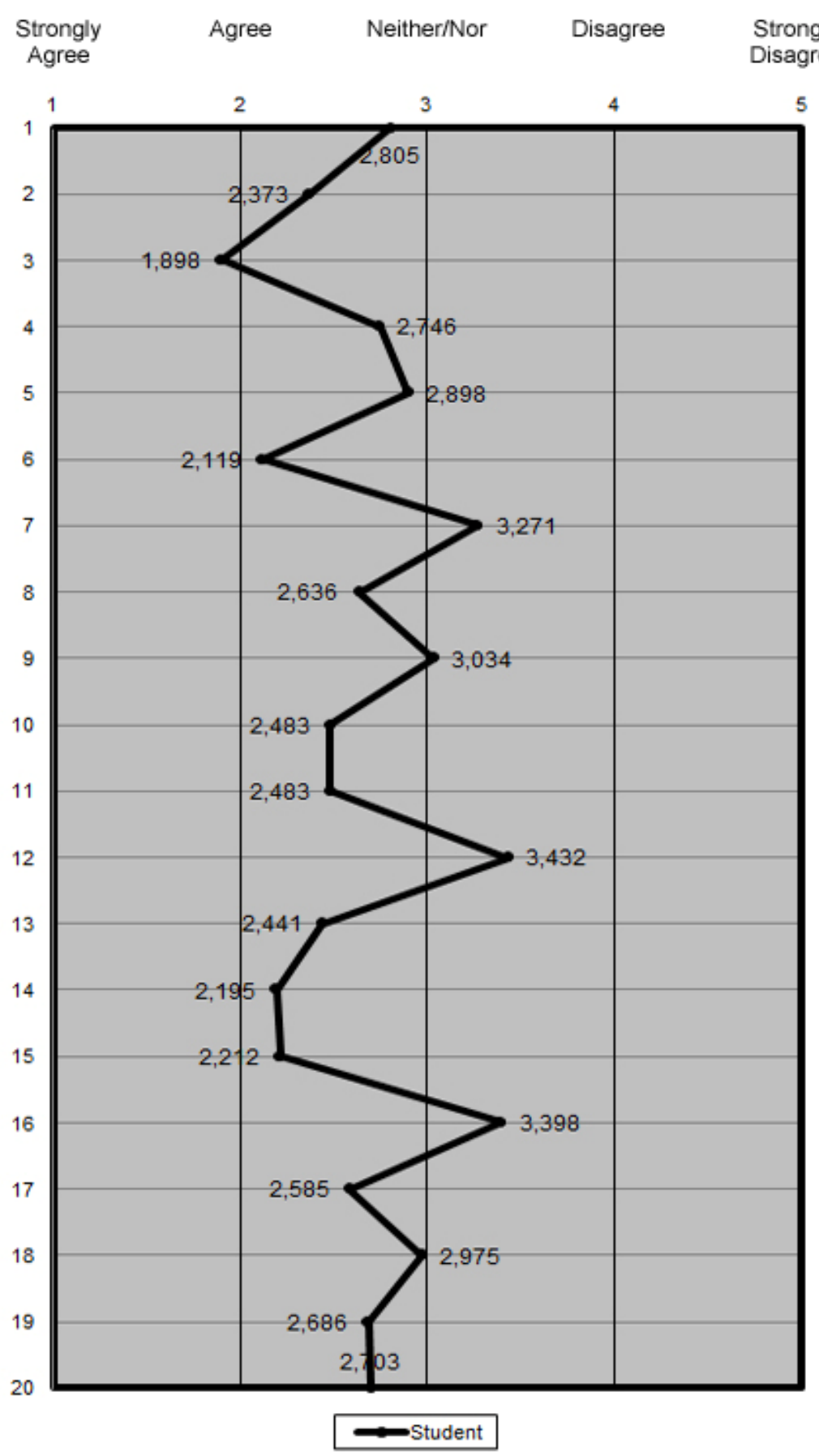

Graphic 1 Arithmetic mean distribution. 
Table 1 Factor groups (according to the responses of students).

\begin{tabular}{|c|c|c|c|c|c|}
\hline Factor no & Factor 1 & Factor 2 & Factor 3 & Factor 4 & Factor 5 \\
\hline $\begin{array}{l}\text { Questions/ } \\
\text { Statements } \\
\text { and } \\
\text { correlation } \\
\text { values }\end{array}$ & $\begin{array}{l}\text { 14. The steel structure } \\
\text { of the inner street } \\
\text { creates a modern } \\
\text { impression } 0.810 \\
4 \text {. The details, } \\
\text { materials, colors and } \\
\text { decoration of the } \\
\text { building is nice } 0.753 \\
2 \text {. The exterior of the } \\
\text { building is nice } 0.667 \\
6 \text {. The size of the } \\
\text { entrance space is } \\
\text { relaxing } 0.655 \\
10 . \text { From each floors } \\
\text { seeing the entrance and } \\
\text { the street is nice } 0.571 \\
1 . \text { Building itself and } \\
\text { the entrance represents } \\
\text { that it's an university } \\
\text { building } 0.522\end{array}$ & $\begin{array}{l}\text { 12. Suitable for } \\
\text { disabled people in } \\
\text { inside and outside } \\
0.657 \\
\text { 16. I spent time } \\
\text { during the breaks in } \\
\text { atrium } 0.490 \\
8 \text {. The entrance space } \\
\text { (street) is in adequate } \\
\text { size for activities } \\
0.489 \\
\text { 3. The building is safe } \\
0.472 \\
18 . \text { All the common } \\
\text { spaces and areas in } \\
\text { this building } \\
\text { contribute to } \\
\text { friendship } 0.459 \\
13 \text {. The inner street is } \\
\text { airiness and } \\
\text { spaciousness } 0.427 \\
15 . \text { The atrium is } \\
\text { luminous and } \\
\text { spaciousness } 0.330\end{array}$ & $\begin{array}{l}\text { 20. I like the fact that } \\
\text { of cafeteria spills over } \\
\text { the inner street } 0.703 \\
19 . \text { The location of } \\
\text { the cafeteria is proper } \\
0.702 \\
11 . \text { The visual } \\
\text { integration of interior } \\
\text { and exterior is } \\
\text { achieved } 0.415\end{array}$ & $\begin{array}{l}\text { 7. The entrance space } \\
\text { is perceived as a street } \\
\text { rather than a hall } \\
0.760 \\
9 . \text { Entrance hall } \\
\text { mainly used in winter } \\
0.530 \\
17 . \text { In upper floors the } \\
\text { corridors around the } \\
\text { atriums and inner } \\
\text { street are wide } \\
\text { enough to spend time } \\
-0.477\end{array}$ & $\begin{array}{l}\text { 5. After entrance } \\
\text { access to } \\
\text { administration and } \\
\text { education blocks is } \\
\text { easy } 0.712\end{array}$ \\
\hline Variables & $\begin{array}{l}\text { *Identity } \\
\text { *Modern effect } \\
\text { *Visual quality }\end{array}$ & $\begin{array}{l}* \text { Social relation } \\
\text { *Dimension } \\
\text { *Spaciousness }\end{array}$ & *Space organization & $\begin{array}{l}\text { *Functional value } \\
\text { *Dimension }\end{array}$ & $\begin{array}{l}\text { *Circulation } \\
\text { *Space organization }\end{array}$ \\
\hline Factor name & $\begin{array}{l}\text { GENERAL } \\
\text { EVALUATION } \\
\text { (VISUAL QUALITY) }\end{array}$ & $\begin{array}{l}\text { SOCIAL \& SPATIAL } \\
\text { IMPACT }\end{array}$ & $\begin{array}{l}\text { SPACE } \\
\text { ORGANIZATION }\end{array}$ & FUNCTIONALITY & CIRCULATION \\
\hline
\end{tabular}

\subsection{Discussion Notes on Observation of the Building}

When the observation sheets of the building were examined, it was determined that nearly all the spaces tend to be used as they are proposed in design phase. However, it is observed that proper equipment was not utilized towards the effective and intended use of all locations.

The entrance floor of the building which is organized to be used as an inner street is mostly used for passing and a small part of it is occupied by a café and a rounded sitting unit that created with standard units of university. On the same floor also the courtyards between classes are not organized according to the design project (sitting units, information boards, etc.). The basement (garden) floor left just for circulation. There is only a small photocopy room added and the café was not realized. The amphitheater is not accessible because the door of the building to backyard is usually locked. And at the second floor galleries because of the lack of the sufficient furnishing to support study, chat, meeting etc. is empty.

\subsection{Notes on the Interview}

As the conclusion of the meetings with teachers and the administration, we observe that traditional foreign language education continues in that most of the education takes place in classrooms. The fact that the building is only $2 / 3$ completed leads to capacity issues, mainly in classrooms. The administration has made demands regarding the more effective use of the entire building in order to enhance the quality of education and has communicated its request for the more effective use of the internal streets and the courtyards during non-classroom hours. The most important of these demands is for a new plan in order to render the internal streets and courtyards more suitable for use as 
places for meeting and study (via being equipped with the appropriate furniture, such as tables, chairs, couches, etc.). Through these meetings, we understand that there are on-going discussions among experts for an imminent comprehensive reorganization of the educational system.

\section{Findings on the Research Hypothesis}

\subsection{Evaluation of Section 1}

General Building Features: Representing the identity of a "Technical University".

When building characteristics are explored in accordance with the two fundamental design principles, the responses are spread along five factor groups and when the responses of all the subjects were evaluated, the primary factor was found to be "visual quality". This factor is related to the image of the inner street, which is the main design decision to give the building its character. This result demonstrates that the design decisions have been implemented in a way that generates the desired effect on the users. The fact that the primary factor that emerges from an evaluation of the students' responses is visual quality, reinforces this conclusion. The arithmetic mean distribution of "General Building Features" display that students evaluated the whole building as "nice" in appearance and especially evaluated inner street and entrance hall as "safe" (1.898), "modern" (2.195), "airy" and "spacious" (2.441). However beside these positive evaluations, they also stressed out the negative aspects of accessibility in design.

\subsection{Evaluation of Section 2}

Social Areas: Solidarity and social interaction in informal activity areas.

- Evaluation of the inner street

The survey has revealed that students do not perceive the main entrance as a street. The emptiness of this area and shortcomings related to the furniture that would facilitate its more effective use as a meeting place are important factors in this perception. As a result of this and the requests received from the administration, a new plan has been developed for this area which utilizes seating groups (Fig. 5) and study tables (Fig. 6) and which will facilitate the gathering of students for social and academic purposes in the non-classroom hours;

- Evaluation of the atriums

Respondents favorably regard design decisions such as the use of the internal courtyard and the suitability of classrooms for groups study. The survey has revealed that students do not effectively utilize the internal courtyards. The emptiness of this area and shortcomings related to the furniture that would facilitate its more effective use as a meeting place are
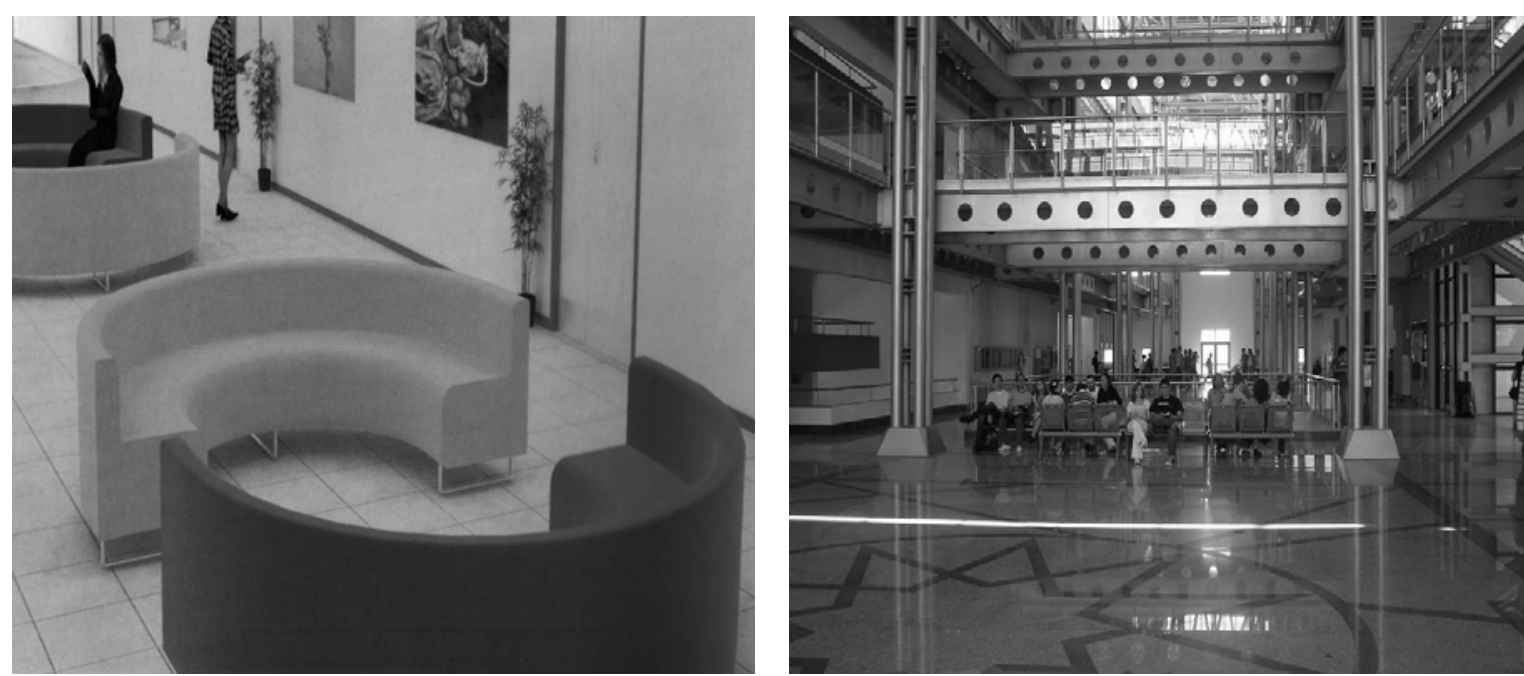

Fig. 5 The furnishing in inner street and connections, Ofisline 2009/2010 Catalog, p. 80 [10]. 


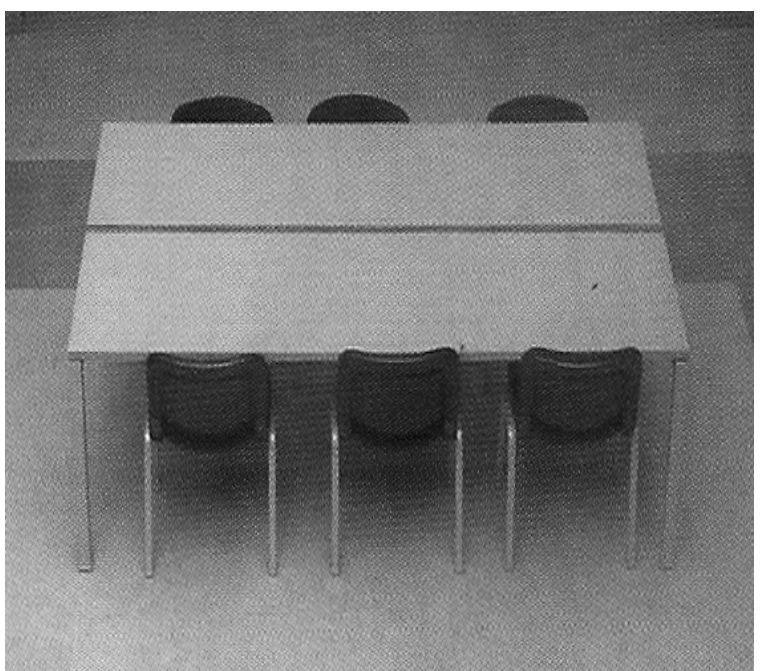

Fig. 6 The study tables which are located at upper floor galleries, Ofisline 2009/2010 Catalog, p. 87 [10].
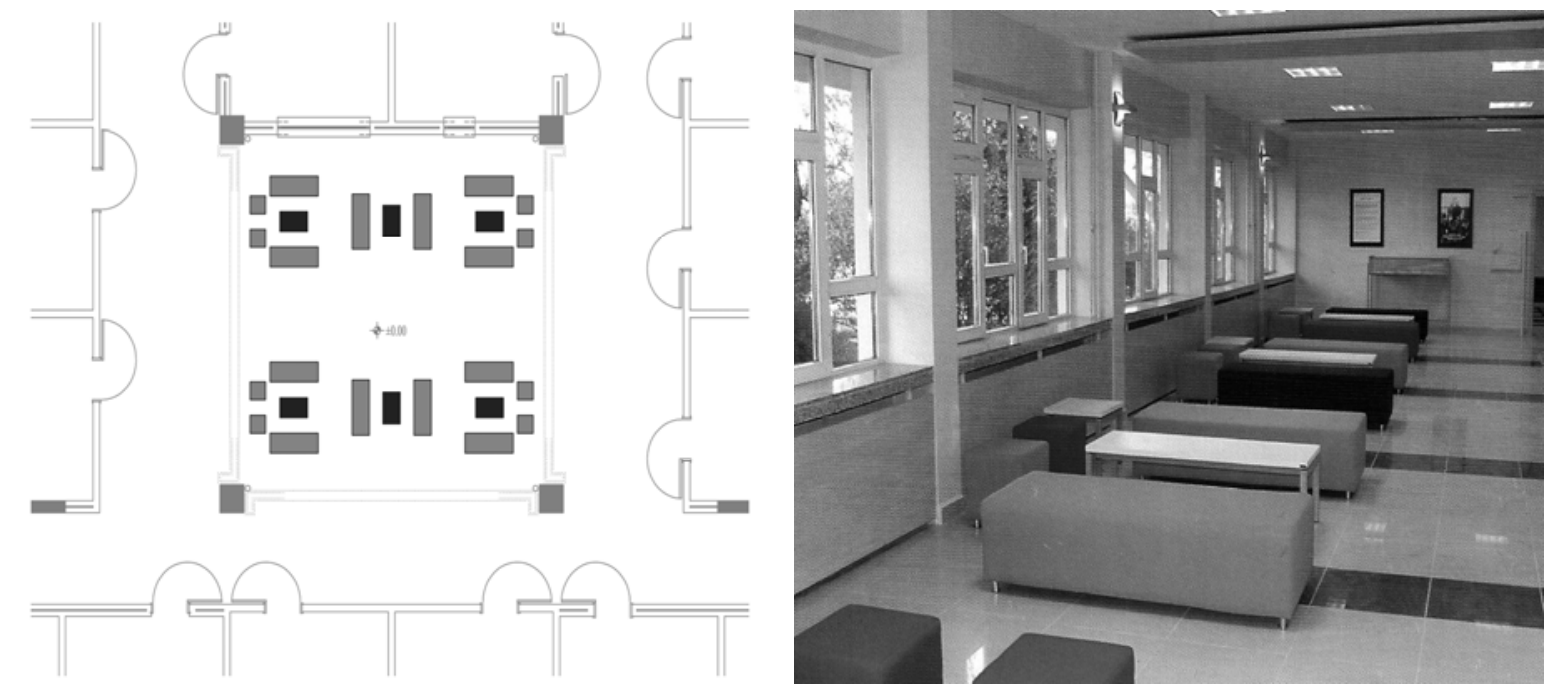

Fig. 7 The furnishing in atriums and the chosen seating groups, Ofisline 2009/2010 Catalog, p. 78 [10], after the contribution of the result of POE study, in recent years the atriums were furnished according to the design aims to encourage the social relations between students and lecturers especially during the breaks. In the atriums three seating groups are organized to meet this interaction.

important factors in this perception. In response to this finding, organizing seating groups (Fig. 7) is suggested in internal courtyards in order to help encourage social interaction.

\section{Conclusions}

In this study, a POE has been carried out to measure the performance of a university building specifically designed, with due regard to end user wishes, for foreign language education. Main objective of the study was to identify to what extent user requirements had been met with internal streets and atriums at educational blocks, which are distinctive features for interactive language education and encouraging student socialization.

As part of the study that included interviews, analysis, surveys and evaluations, it has been identified how the building worked and problems this has led. For the purpose of using the building compatible with the aims that are identified in the design process; short, mid and long-term plans are set to produce solutions. In accordance with the sustainability of the building, proposed solutions are given below.

- P (Problems) and short term S (solutions): 
P1. Accessibility for disabled people in interior and exterior spaces;

$\mathrm{S} 1$. The execution of the necessary arrangements in order to ensure that disabled users have access the inner street comfortably (through the inner street - door connection) and the construction of an elevator (elevator shaft and related machinery space are included in the project) to ensure vertical circulation within the movement.

$\mathrm{P} 2$. Inefficient activities in inner street and courtyards;

$\mathrm{S} 2$. Flexible space organization and mobile furniture are proposed but in the future, informal activities should be organized by students and also guidance of the teachers are needed. This can be achieved by reviewing the course programs and general foreign language education system in YTU.

P3. Inadequate classroom capacities and dimensions in accordance with the number of students;

S3. Capacity problems arising from class schedules; until $2.00 \mathrm{pm}$ at the SFL and ongoing building work could be mitigated through efficient use of existing spaces;

- P (Problems) and mid-term S (solutions):

P1. Relations of cafe and outdoor spaces;

S1. Remodeling of the café and linking with the garden is quite significant in terms of internal-external interaction.

P2. Requirement of a new meeting hall;

$\mathrm{S} 2$. In addition to the 120 persons of capacity, multi-purpose room on the first floor, a requirement for a more flexible and more spacious room has emerged. Following meetings with the directorate, use of the existing space on the garden floor (below the gallery void) has been decided and project studies will be undertaken in line with this decision;

- P (Problems) and long-term S (solutions):

P1. Inadequate space capacities and dimensions, Classrooms capacities and dimensions in accordance with the number of students.

S1. Because the $2 / 3$ of the building has been completed at the first stage, the whole of the building is required to be completed. And also to gain larger classrooms, some classes could be unified by removing the walls between them.

As a result, the POE conducted in SFL has a significance to be the first one in Turkey. The findings of the study will lead to a path for other faculty buildings in YTU Davutpaşa Campus area in the process of design. Furthermore, the study has profitable results for every kind of educational buildings. The interaction between the features of the building design and the users of the building will set in motion the true lifespan of the building and its constituent sites, thereby becoming the indicator of the function and identity of modern education.

\section{References}

[1] M. T. Akbulut, Visual evaluation method of earthquake vulnerability risk of the constructed buildings, Ph.D. Thesis, Yildiz Technical University, Graduate School of Natural and Applied Sciences, Istanbul, 2004.

[2] C. Baytin (Polatoğlu), A. Kiran and M. Tunbis, Colour preferences in architectural design studios, Architectural Science Review 48 (4) (2005) 317-328.

[3] OECD, What Schools for the Future? Education and Skills, OECD (Organisation for Economic Cooperation and Development), Paris, France, 2001.

[4] A. J. Lackney, Thirty-three educational design principles for schools \& community learning centres, Educational Design Institute Mississippi State University, 2000, available online at: http://www.edi.msstate.edu/articles33design.php.

[5] T. Heitor, Potential problems and challenges in defining international design principles for schools: Evaluating quality in educational facilities, OECD/PEB (Programme on Educational Building), 2005, pp. 44-54, available online http://www.oecd.org/dataoecd/26/36/37905247.pdf.

[6] G. Baird, J. Gray, N. Isaacs, D. Kernohan and G. McIndoe, Building Evaluation Techniques, McGraw-Hill Professional Publishing, New York, 1995.

[7] W. F. E. Preiser and J. C. Vischer, Assessing Building Performance, Elsevier, Oxford, 2005.

[8] D. J. M. van der Voordt and H. B. R. Van Wegen, Architecture in Use, Architectural Press, Oxford, 2005.

[9] J. Zeisel, Inquiry by Design: Tools for Environment Behavior Research, Cambridge University Press, Cambridge, 1995.

[10] Ofisline 2009/2010 Catalog, available online at: http://www.ofisline.com.tr. 